\title{
Psycho-legal challenges facing the mentally retarded rape victim
}

F J W Calitz, BA Hons, MA (Clin Psychol), DPhil

Department of Psychiatry, Faculty of Health Sciences, University of the Free State, Bloemfontein

Persons with mental retardation face multiple emotional, cognitive and social challenges. Mental health professionals increasingly agree that individuals with mental disabilities are more vulnerable to sexual abuse and exploitation than the general population. They are particularly exposed to peril because of their often lifelong dependence on caregivers, relatively powerless position in society, emotional and social insecurities, and lack of education regarding sexuality and sexual abuse. Shortcomings and discrepancies in the medical and legal definition of mental retardation make the position of such individuals even more difficult. These shortcomings are discussed in the article.

Crime is a prominent and perplexing phenomenon in South Africa. It affects people from all races and socio-economic groups, and has far-reaching consequences for victims.' Because sexual violence against women and children is rife in South Africa, the country has been branded the 'rape capital of the world'.2

Official statistics for the year ending March 2010 showed an average reported daily crime rate of 47 murders, 177 robberies and 38 car hijackings in South Africa. ${ }^{3}$ A total of 71500 cases of sexual offences were reported to the South African Police Services (SAPS) from April 2008 to March 2009. There were 4518 instances of sexual offences reported in the Free State province during this period. ${ }^{4}$

Only two research articles dealing exclusively with the plight of mentally retarded rape survivors in South Africa have been published. Pillay and Sargent ${ }^{5}$ evaluated 10 rape survivors with possible mental retardation over the 12-month period ending 30 September 1999. In his second study, Pillay ${ }^{6}$ evaluated 106 rape survivors with possible mental retardation over a 3-year period ending 31 March 2008. For her Master's study, Todd ${ }^{7}$ assessed 144 complainants during a 1-year period in the Sexual Abuse Victim Empowerment Programme of the Western Cape. At the Free State Psychiatric Complex (FSPC) in Bloemfontein, 170 rape survivors with mental retardation were referred for assessment by the courts from 2003 to 2009. Forty (23.5\%) of the referrals were made in 2009. In the first quarter of 2010, 46 new cases have been evaluated. Should matters continue at this rate for the remainder of the year, more cases will be seen in 2010 than in the entire preceding period.

Despite its prevalence, rape remains one of the most underreported crimes in South Africa. It has been estimated that only in 35 rapes or attempted rapes are actually reported to the police. ${ }^{8}$
There is growing consensus among mental health professionals that children, adolescents and adults with mental retardation and other forms of mental illness are more vulnerable to sexual abuse and exploitation than the general population. These individuals are especially vulnerable because of their often lifelong dependence on caregivers, their relatively powerless position in society, emotional and social insecurities, and their lack of education regarding sexuality and sexual abuse. People with mental retardation are often sexually stigmatised and perceived as asexual, sexually incompetent or possessing an uncontrollable libido and perverted sexual habits, making them targets for sexual abuse as they lack sufficient knowledge regarding sexual matters. They do not know their rights and cannot make informed decisions. Because they are not regarded as sexual beings by the rest of the society, their plight is readily kept secret by perpetrators, sometimes with their own help. ${ }^{5}$ Sometimes their predicament only becomes known when the perpetrator fails to keep a promise made to them, and they then complain to a caretaker or family member.

Assessing people with mental retardation to determine whether they will be competent to act as witnesses is challenging, as people with mental retardation rarely appear as witnesses in court. The situation is exceptionally difficult when the person with mental retardation as the victim of sexual abuse is the sole witness against the accused. Historically, justice systems, and particularly the criminal justice system, have regarded people with mental retardation as unreliable witnesses. It has been believed that their memory systems are inherently defective, and it has therefore been assumed that they are susceptible to suggestion and lack the skills to accurately report the events that took place. Recalling information, in other words remembering, can often be difficult for people with mental retardation, because they tend to take longer to encode, understand and store information than their peers in the general population. This influences the reliability of a witness with mental retardation in giving an accurate and consistent account of the alleged rape.

For us to understand the psycho-legal dilemma of the rape survivor who is mentally ill, especially with the current trend to integrate citizens with mental retardation into the community, away from institutionalised care, it is essential that we have a basic understanding ${ }^{9}$ of mental retardation and legislation-regulated aspects regarding mental health and mental retardation in South Africa.

\section{The complex nature of the term mental retardation}

There can be no doubt that intellectual gifts have been distributed on a continuum from meagre to abundant for as long as mankind has walked the earth. Yet, through the ages, the understanding and treatment of persons with mental retardation have moved like a 
pendulum between extremes. At one extreme, persons with mental retardation have been considered 'children of the Good God'. To this day, movies such as Being There and Forrest Gump and a character like Bertie in the series Egoli convey the message that persons with mental retardation are somehow blessed with simpler, more straightforward understandings of basic human truths. Yet, at the same time, such persons have also been vilified. The word cretin takes its origin from Christian or Christ-like, yet its modern definition includes descriptors such as stupid, vulgar and insensitive. To this day, society wrestles with the exact nature of such persons. ${ }^{10}$

\section{What is mental retardation?}

Mental retardation, according to the Diagnostic and Statistical Manual of Mental Disorders, 4th edition (DSM-IV-TR), is defined as significantly sub-average general intellectual functioning (having an IQ of 70 or less) that is accompanied by significant limitations in adaptive functioning in at least two of the following skills areas: communication, self-care, home living, social/interpersonal skills, use of community resources, self-direction, functional academic skills, work, leisure, health and safety. The onset must occur before age eighteen years.

The International Classification of Diseases (ICD-10) $)^{12}$ defines mental retardation as a condition of arrested or incomplete development of the mind, which is especially characterized by impairment of skills manifested during the developmental period, skills which contribute to the overall level of intelligence, i.e. cognitive, language, motor, and social abilities.

The American Association of Mental Retardation's ${ }^{13}$ definition reads as follows: A disability characterized by significant limitations both in intellectual functioning and in adaptive behavior as expressed in conceptual, social, and practical adaptive skills ... Adaptive behavior is the collection of conceptual, social, and practical skills that people have learned so they can function in their everyday lives. Significant limitations in adaptive behavior impact a person's daily life and affect the ability to respond to a particular situation or to the environment.

\section{Legislation and mental retardation}

A major difficulty is that the different pieces of legislation do not always appear to be synchronous in the terms used to refer to mental illness or mental retardation. The legislation is also not in harmony with the scientific terms used by clinicians who are required to provide expert evidence in such cases. This is one of the main reasons why rape survivors who are believed to have mental retardation are subjected to a somewhat different sequence of legal events compared with those without this disability.

The Mental Health Care Act 17 of 2002 (section 1) 14 governs mental health in South Africa. This Act makes no mention of the term mental retardation. The Mental Health Care Act defines a mental illness as a positive diagnosis of a mental health-related illness in terms of accepted diagnostic criteria made by a mental healthcare practitioner authorised to make such diagnosis.
The closest reference to mental retardation is the use of the term severe or profound intellectual disability (section 1), which is defined as a range of intellectual functioning extending from partial self-maintenance under close supervision, together with limited selfprotection skills in a controlled environment through limited self-care and requiring constant aid and supervision, to severely restricted sensory and motor functioning and requiring nursing care. What is not clear from the legislation is whether these terms are meant to be synonymous with mental retardation or mental illness. It is also not clear whether severe or profound intellectual disability as used in the Mental Health Care Act is intended to be synonymous with the terms severe mental retardation and profound mental retardation as used in the DSM-IV or the ICD-10. Also, does it by implication mean that people with mild and moderate mental retardation do not fall under the Mental Health Care Act 17 of 2002?

Under South African law, for many years statutory prescriptions on sexual activity were contained in the Sexual Offences Act of 1957..$^{15}$ The Sexual Offences Act regards it as an offence to have or to attempt to have unlawful carnal intercourse with a male or female 'idiot' or 'imbecile.' However, it should be proved that such a person (the perpetrator) knew that such male or female was an 'idiot' or 'imbecile, to be found guilty of an offence (section 15).

The Criminal Law (Sexual Offences and Related Matters) Amendment Act 32 of $2007^{16}$ also does not refer to mental retardation. Instead, reference is made to a person who is mentally disabled which means a person affected by any mental disability, including any disorder or disability of the mind, to the extent that he or she, at the time of the alleged commission of the offence in question, was -

(a) unable to appreciate the nature and reasonably foreseeable consequences of a sexual act;

(b) able to appreciate the nature and reasonably foreseeable consequences of such an act, but unable to act in accordance with that appreciation;

(c) unable to resist the commission of any such act; or

(d) unable to communicate his or her unwillingness to participate in any such act.

What is not clear from the legislation is whether'mentally disabled' is meant to be synonymous with mental retardation or mental illness.

Section 57 (2) of the same Act states that, notwithstanding anything to the contrary in any law contained, a person who is mentally disabled is incapable of consenting to a sexual act.

The question regarding the rape survivor's ability to consent to sexual intercourse is a fairly complex matter. Todd ${ }^{7}$ found that people with mental retardation are not able to consent to sexual interaction, regardless of the degree of impairment. The level of their intellectual functioning is considered to be equivalent to that of minors. Evaluation of the complainant's ability to consent should focus on the event in question, and include information on the 
individual's understanding of sexual behaviour and the context of normal sexual relationships; knowledge of the consequences of sexual intercourse, for example, pregnancy and infections; ability to make an informed decision to engage in sexual intercourse, based on the above; awareness and understanding of the right to say 'no'; and ability to resist or say 'no' in the context.

Section 68 of the Criminal Law (Sexual Offences and Related Matters) of 2007 goes further and states that whenever... it appears to such court that it would expose any witness under the biological or mental age of eighteen years to undue mental stress or suffering if he or she testifies at such proceedings, the court may ... appoint a competent person as an intermediary in order to enable such witness to give his or her evidence through that intermediary. In July 1993, Section 170A of the Criminal Procedure Act ${ }^{18}$ introduced an intermediary system for witnesses under the age of 18 years. Pillay and Sargent ${ }^{5}$ advocated already in 2000 that provision also be made for the appointment of intermediaries for adults with mental retardation who were required to give evidence in rape and sexual abuse cases. The preparation and training of such intermediaries is indeed a very important consideration. These individuals must have psychological training and be skilled in interviewing people with cognitive and intellectual impairments. Questioning the rape survivor with mental retardation through a trained intermediary would filter out the intimidatory aspect of questioning, thus minimising the perceived threat and discomfort of the witness, and facilitating credible testimony. This in turn may contribute to the successful prosecution of alleged perpetrators, and perhaps significantly improve the conviction rate.

The Criminal Law Amendment Act 105 of $1997^{19}$ (Section 51) provides for a minimum life imprisonment sentence for a person convicted of raping a mentally ill woman, as contemplated in section 1 of the Mental Health Act 18 of 1973. With the Mental Health Care Act No 17 of 2002 in place, mentally ill will need to be defined in those terms. In this regard, the classification according to both the DSM-IV and ICD-10 should be reconsidered. Both the DSM-IV and the ICD10 use the term 'mental disorder' and classify mental retardation as a mental disorder. It is also important to mention that there are different degrees in the seriousness of a mental disorder and mental retardation. For example, a mildly mentally retarded rape victim is likely to give adequate testimony and will be able to understand and relate what happened to them, while a profound or severely mentally retarded victim will not be able to do that. It will therefore be possible for a person convicted of raping a severely mentally retarded victim to receive a minimum life imprisonment sentence.

One of the principles of criminal law and procedure is that only persons who are capable of understanding the nature of the trial proceedings or conducting a proper defence can be tried. The basis of this rule is said to be that the trial should take place in the accused person's mental as well as physical presence. This principle is reflected in section 77 of the Criminal Procedure Act, ${ }_{18}^{18}$ in terms of which an enquiry is made into the capacity of an accused to understand the proceedings so as to be able to conduct a proper defence. This means that an accused who suffers from mental illness or defect may as a result be not be fit to stand trial.

When an accused is found not fit to stand trial, he/she is detained in a mental hospital as a state patient, until such time as they become fit to be tried. Section 77 is in sharp contrast with Section 194 of the Criminal Procedure Act ${ }^{18}$ of 1977, which states that no person appearing or proved to be afflicted with mental illness ... and who is thereby deprived of the proper use of his reason, shall be competent to give evidence while so afflicted or disabled. In this regard Tharinger et al. ${ }^{20}$ pointed out that developmentally sensitive procedure is invaluable in eliciting evidence from survivors with mental retardation that may lead to the prosecution of offenders. It is therefore important that police personnel understand these issues and have access to the psychological support they require to assist these survivors. If a rape survivor with mental retardation is considered incompetent and denied the right to testify in court, the court has to rely on sufficient evidence obtained by the police investigation and other forms of evidence (for example DNA tests). Without such evidence, the perpetrator walks out free. Failure to prosecute and convict such offenders would allow for continued abuse without fear of retribution.

\section{What are the main psycho-legal challenges surrounding the rape of persons who are mentally retarded, and how can we deal with these challenges?}

It is clear that different terms are used by legislation to describe mental retardation. Do we have to use the terms mentally disabled, mentally ill, mental illness, idiot or imbecile, under the biological or mental age of 18 years, cognitive deficits or cognitive handicap, or can it be described as a severe or profound intellectual disability? In this area an obvious need exists to come to an agreement to use a definition for mental retardation that is acceptable to both the mental health professional and the law. In this regard, classification according to both the DSM-IV and ICD-10 should be seriously reconsidered. They are respectively accepted in the USA and Europe as classification systems for mental illness. The differences among mental health professionals and the law regarding the definition of mental retardation should therefore be addressed and sorted out.

The first question is usually with regard to the intellectual level of the individual. Specifically, an assessment of the level of mental retardation (if present) is required. Of course, for the court the value of this finding lies not in the nomenclature, but in the individual's abilities with regard to decision making, consenting to sexual intercourse, and providing testimony and participating in court proceedings. While this question implies assessment of intellectual functioning, an evaluation of social competence is also particularly useful. Social competence refers to the individual's ability to cope with everyday challenges, and solve problems that arise within his/ her socio-cultural context. It encompasses broader life experience variables rather than simply cognitive and abstract constructs, and therefore has greater value and meaning in real-life situations." 
It is important to know the intellectual level of the complainant because mental retardation is not a homogeneous category, and individuals with different severities of the condition will have different capabilities in providing testimony. For a certain subgroup of these individuals, severely impaired language and verbal skills will mean they are not able to provide the court with verbal testimony in the conventional manner. This applies mainly to individuals with profound mental retardation as well as some in the severe range.

It is commonly understood that appearing in court provokes anxiety in most normal people. For vulnerable witnesses, such as children and people with mental retardation, the situation is even more difficult. Difficulties may arise during testimony owing to the historically adversarial and often intimidatory approach to witnesses in the courtroom. In traumatic situations, mentally retarded individuals may become distressed, confused and withdrawn, and may experience greater speech difficulties. Consequently they may be viewed as unreliable witnesses. It is also accepted that crossexamination is a prerogative of the defence. ${ }^{5}$

The question relating to the rape survivor's ability to testify includes her/his competency to give an account of the events, understand questions put to her/him, and respond to questions and crossexamination. Perhaps the least complicated approach is to consider the individual's ability to tell the story in a simple way. ${ }^{5}$ Research has demonstrated that even very young children, from the age of about 4 years, can provide meaningful information about their experiences when they are interviewed in a careful and supportive manner. ${ }^{21}$

According to Todd, for vulnerable witnesses such as children and people with mental retardation, familiarity with the setting and procedure can make the difference between competence and incompetence in court as a witness. Liaison with the prosecutor/s is essential. The aim should be to run the court preparation sessions weeks before the due date of the trial. A number of steps can be followed when conducting court preparation. Firstly, it is essential to familiarise the complainant with the physical setting of the courtroom, which includes explaining where he/she will sit when giving the evidence, where the prosecutor will stand, where the defence attorney will stand, and where the magistrate will be seated.

Todd' further argues that it is important to make sure that the complainant meets the prosecutor handling the case ahead of time. The role of each lawyer needs to be explained simply. For example, the prosecutor will help the complainant tell her/his story and the defence attorney will help the accused tell her/his story. The magistrate will listen to both to decide, following rules, the fate of the accused. Next it is essential to emphasise the importance of telling the truth, but in a non-offensive manner.

Subsequently, it must be emphasised that the complainant has the right to ask for a question to be repeated or rephrased. It is important to understand the question being asked so the complainant can answer truthfully without guessing the answer due to lack of understanding. Also make sure the complainant understands that it is acceptable not to know an answer to a question. It is good enough to respond with'l do not know'. Finally, it may be helpful for the complainant to know that she/he can use their own words in describing the account of what happened?

The question of whether the complainant's mental deficiency is evident to the average person is an interesting one. The reason for the question appears related to the common defence that the sexual contact was consensual (in the case of complainants older than 16 years of age). Certainly the state would usually contest this by arguing, inter alia, that the complainant was not able to consent to sexual intercourse by virtue of her/his intellectual disability. The tactical defence response is that the accused is not a mental health expert and therefore could not be expected to know that the complainant has a mental disability. Answering this question is much easier in the case of rape survivors functioning in the range of moderate and lower mental retardation, where the cognitive disability is more noticeable. Nevertheless, in answering this question it is important to point out (especially if the expert is in court and has the latitude to explain) the extent to which normal social interaction preceding a sexual encounter would reveal the complainant's general level of functioning. ${ }^{17}$

From Section 68 of the Criminal Law (Sexual Offences and Related Matters) Act of 2007, it is also not clear what is meant by under the mental age of eighteen years. Mental age refers to an age-normed level of performance on an intelligence test. The IQ is an expression of a person's mental age as a percentage of the chronological age. The mental age is usually equal to the chronological age. For example, an adult who is intellectually disabled, with an IQ of approximately 50 - 69, may have a mental age from 9 years to less than 12 years. The mental age assists the court in understanding on which level the complainant functions. This means that you are dealing with an adult, with all the needs of an adult but with a child's mind.

Another important role player in this legal battle is the police. If a rape survivor with mental retardation is considered incompetent to testify and insufficient evidence is available, the case will be dismissed and the perpetrator walks out free. Failure to prosecute and convict such offenders would allow for continued abuse without fear of retribution.

\section{Conclusion}

Crime in South Africa is a prominent and perplexing phenomenon. Persons with mental retardation are exceptionally vulnerable owing to their complex disabilities on intellectual and social levels. The mentally retarded rape victim has to face serious psycho-legal challenges. There is clearly a need for more work in this area in order to develop the best practical approach for the legal and mental health system. 


\section{References}

1. Du Plooy A. Phenomenological analysis of the subjective meaning of being part of the police services at a police station in the Uthungulu District. Unpublished master's dissertation, University of Zululand, 2009

2. Ludski H. Straight to jail for 40 years for rapists: definition of the crime is broadened in proposals. Sunday Times, Johannesburg, 5 September 1999, p. 2.

3. African Press International South Africa: Murder rate down $8.6 \%$, crime stats show. Posted by African Press International on 10 September 2010. htttpp://africanpress.wordpress. com/2010/09/10South African-murder-rate-down-8-6-crimestats-show/ (accessed 6 April 2011).

4. SAPS (South African Police Services). Crime in the RSA for April to March 2008/2009. www saps.gov.za/statistics/reports/crimestats/2009/_pdf/rsa_total.pdf (accessed 14 December 2009).

5. Pillay AL, Sargent C. Psycho-legal issues affecting rape survivors with mental retardation. S Afr J Psychol 2000;30:9-13

6. Pillay AL. An audit of competency assessments on court-referred rape survivors in South Africa. Psychol Rep 2008;103:764-770.

7. Todd RMJ. Sexual Abuse Victim Empowerment Programme: An archival study assessing the relationship between demographics and level of intellectual functioning. Unpublished master's dissertation, Stellenbosch University, 2005.

8. Commission on Gender Equality. Report of the Commission on Gender Equality Information and Evaluation Workshop, KwaZulu-Natal Province. Commission on Gender Equality, 1997.

9. Morano JP. Sexual abuse of the mentally retarded patient: medical and legal analysis for the primary care physician. Prim Care Companion J Clin Psychiatry 2001;3:126-135.

10. King BH, Hodapp RM, Dykens EM. Mental retardation. In: Sadock BJ, Sadock VA, eds. Kaplan \& Sadock's Comprehensive Textbook of Psychiatry. 8th ed. Baltimore, Md: Lippincott Williams \& Wilkins, 2005.
11. American Psychiatric Association. Diagnostic and Statistical Manual of Mental Disorders. 4th ed., text revision (DSM-IV-TR). Washington, DC: American Psychiatric Association, 2000.

12. International Statistical Classification of Diseases and Related Health Problems. 10th revision version, 2007. http://apps.who.int/classifications/apps/icd/ icd10online (accessed 20 January 2010)

13. Johnston C, Liddle J. The Mental Capacity Act 2005: a new framework for healthcare decision making. J Med Ethics 2007;33:94-97.

14. Department of Justice, Republic of South Africa. Mental Health Care Act, 2002 (No. 17 of 2002). Government Gazette, 6 November 2002. Pretoria: Government Printer, 2002.

15. Republic of South Africa. Government Gazette: Sexual Offences Act of 1957. Cape Town: Government Printer, 1957

16. Department of Justice, Republic of South Africa. The Criminal Law (Sexual Offences and Related Matters) Amendment Act 32 of 2007. Cape Town: Juta \& Co., 2007.

17. Pillay AL, Kritzinger AM. Psycho-legal issues surrounding the rape of children and adolescents with mental retardation. J Child Adolesc Mental Health 2008;20:123-131.

18. Department of Justice, Republic of South Africa. Criminal Procedure Act 51 of 1977. http:// www.doj.gov.za/legislation/acts/1977_51\%Bas\%20at2025Apr2008 \%5D.pdf (accessed 15 January 2010).

19. Republic of South Africa. Government Gazette: Criminal Law Amendment Act No. 105 of 1997. Cape Town: Government Printer, 1997

20. Tharinger D, Horton CB, Millea S. Sexual abuse and exploitation of children and adults with mental retardation and other handicaps. Child Abuse Negl 1990;14:301-312.

21. Lamb ME, Sternberg KJ, Orbach Y, Esplin PW, Stewart H, Mitchell S. Age differences in young children's responses to open-ended invitations in the course of forensic interviews.J Consult Clin Psychol 2003;71:926-934. 